\title{
The Role of VEGF in the Diabetic Patients Undergoing Endovascular Therapy of Symptomatic Aortic Valve Stenosis
}

\author{
V. BLÁHA ${ }^{1}$, J. ŠŤÁSEK ${ }^{2}$, J. BIS ${ }^{2}$, J. FORTUNATO ${ }^{1}$, C. ANDRÝS ${ }^{3}$, V. PAVLÍK ${ }^{1}$, \\ P. POLANSKÝ ${ }^{4}$, M. BRTKO ${ }^{4}$, L. SOBOTKA ${ }^{1}$
}

${ }^{1}$ Third Department of Internal Medicine, Metabolism and Gerontology, University Hospital Hradec Králové and Medical Faculty Charles University in Hradec Králové, Czech Republic, ${ }^{2}$ First Department of Internal Medicine - Cardioangiology, University Hospital Hradec Králové and Medical Faculty Charles University in Hradec Králové, Czech Republic, ${ }^{3}$ Department of Immunology and Alergology, University Hospital Hradec Králové and Medical Faculty Charles University in Hradec Králové, Czech Republic, ${ }^{4}$ Department of Cardiosurgery, University Hospital Hradec Králové and Medical Faculty Charles University in Hradec Králové, Czech Republic

Received June 24, 2014

Accepted July 8, 2014

\begin{abstract}
Summary
The aim of this study was to explore changes in plasma vascular endothelial growth factor (VEGF) in aged patients who undergone transcatheter aortic valve implantation or balloon angioplasty for the treatment of aortic stenosis. Plasma VEGF was measured in subjects with diabetes mellitus type 2 (DM) $(n=21$, age $79.2 \pm 1.6$ years) and in non-diabetic subjects (non-DM) ( $n=23$, age $84.4 \pm 0.7$ years), using an ELISA kit. Before the procedure plasma levels of VEGF were significantly lower in DM than in non-DM patients $(P<0.05)$. Plasma VEGF significantly increased in both groups (DM and non-DM) $24 \mathrm{~h}$ $(387 \pm 64$ vs. $440 \pm 30 \mathrm{pg} / \mathrm{ml}, \mathrm{P}<0.05)$ and $72 \mathrm{~h}(323 \pm 69$ vs. $489 \pm 47 \mathrm{pg} / \mathrm{ml}, \mathrm{P}<0.05)$ after the endovascular procedure. However, the VEGF in DM patients was significantly lower compared to non-DM subjects up to one month after the endovascular procedure ( $283 \pm 47$ vs. $386 \pm 38 \mathrm{pg} / \mathrm{ml}, \mathrm{P}<0.05)$. We conclude that increased plasma VEGF in aged patients associates with atherosclerotic aortic valve stenosis. In spite of that plasma VEGF in DM was constantly significantly lower than in non diabetic patients, both before and after the endovascular procedure, possibly reflecting a disturbance of angiogenic/antiangiogenic balance in diabetes.
\end{abstract}

\section{Key words}

Type 2 diabetes mellitus • Aortic stenosis • Vascular endothelial growth factor

\begin{abstract}
Corresponding author
V. Bláha, Third Department of Metabolic Care and Gerontology, University Hospital Hradec Králové and Medical Faculty Charles University in Hradec Králové, Sokolská 581, 50005 Hradec Králové, Czech Republic. Fax: $420495832001 . \quad$ E-mail: blaha@lfhk.cuni.cz
\end{abstract}

\section{Introduction}

Aortic stenosis (AS) is the most frequent heart valve disease and the most common cause of heart valve replacement in the elderly (Otto et al. 1999). It is characterized by massive fibrous thickening of valve leaflets and extensive focal calcification (Ortlepp et al. 2006). The development and progression of AS is an active inflammatory process, including disruption of the basement membrane, subendothelial accumulation of intracellular lipids, lipoproteins and molecular mediators of calcification, together with infiltration of inflammatory cells and activation of local and systemic inflammation (Mohty et al. 2008, Yetkin and Waltenberger 2009). The concept of AS as an atherosclerosis-like process is supported by a number of studies showing that its development is associated with cardiovascular risk factors such as smoking, hypercholesterolemia, and arterial hypertension (Ngo et al. 2001, Pate 2002). However, several lines of evidence suggest differences 
with regard to AS as an atherosclerosis-like process and the occurrence of diabetes mellitus (DM). Atorvastatin (Panahi et al. 2013) nor simvastatin with ezetimibe (Rossebø et al. 2008) in the randomized trials did not reduce the composite outcome of combined aortic valve events and ischemic events in non DM patients with AS. Such therapy reduced the incidence of ischemic cardiovascular events but not events related to aorticvalve stenosis (Rossebø et al. 2008). On the contrary, DM is associated with enhanced inflammation within AS valves, which may contribute to faster AS progression (Natorska et al. 2012). Diabetes mellitus has also been reported to represent a risk factor for AS, however few is known about this association despite the strong impact of DM on coronary atherosclerosis (Katz et al. 2006). Diabetes accompanied by inflammation is thought to play an important role in enhancing the pathophysiological mechanism of atherosclerosis (Jawień 2008).

Vascular endothelial growth factor (VEGF), a $45 \mathrm{kDa}$ heparin-binding growth factor, is a determinant of the rate and extent of angiogenesis in embryonic vasculogenesis and adult vascular remodelling following physiological repair and regeneration (Battegay 1995, Dvorak et al. 1995). VEGF belongs to the growth factors believed to act predominantly on vascular endothelial cells. VEGF is mitogenic for endothelial cells, acting in early phases and at most of the steps in the angiogenic cascade (Ferrara 2001). Increasing evidence suggests a role for VEGF in the pathophysiology of cardiovascular disease (CVD). Elevated plasma VEGF has been shown in patients with hypertension (Felmeden et al. 2003) and diabetes (Hovind et al. 2000, Blann et al. 2002), with levels correlating with measures of endothelial damage/dysfunction and overall cardiovascular risk in hypertensive patients (Felmeden et al. 2003). Furthermore, VEGF has an independent prognostic significance in patients with acute coronary syndromes (Heeschen et al. 2003).

Normal angiogenesis depends on the intricate balance between angiogenic (e.g. VEGF, fibroblast growth factor - FGF2, transforming growth factor TGF- $\beta$, and angiopoietin) and antiangiogenic factors (angiostatin, endostatin, thrombospondins) (Goodwin 2007). Although the impairment of collateral vessel development is well established in diabetic patients (Abaci et al. 1999), the factors responsible for this alteration are not well known. In a previous study on twenty patients that placed undergone coronary artery bypass surgery, increased VEGF expression in the myocardium of diabetic patients in comparison with non-diabetic patients, and decreased expression levels of VEGF receptor 1 and 2, has revealed a relationship between diabetic cardiovascular complications and neovascularization dysfunction (Sasso et al. 2005).

For patients with severe symptomatic AS, endovascular intervention with transcatheter aortic valve implantation (TAVI) or ballon angioplasty (BA) is an effective treatment modality. Successful valve implantation or angioplasty results in marked symptom relief and age-corrected survival becomes nearly normal (Conrotto et al. 2014). However, there are no data on plasma VEGF and its relationship with endovascular interventions with TAVI or BA in patients with type 2 diabetes.

Thus, the aim of this work is to study the role of plasma VEGF as the strongest known angiogenic factor in the elderly diabetic patients with advanced atherosclerosis and evaluate the impact of the endovascular therapy of symptomatic severe aortic valve stenosis. We hypothesized that increased plasma VEGF would be associated with aortic stenosis. We tested our hypothesis in a cross-sectional study with elderly patients suffering from severe aortic stenosis. In addition we hypothesized that plasma VEGF levels would change after the endovascular treatment independently from diabetes mellitus. For that, we divided the study group in patients with and without diabetes.

\section{Material and Methods}

\section{Subjects}

We performed a cross-sectional study on 44 elderly patients (Table 1 ) aged 79.6 5.6 years who undergone transcatheter aortic valve implantation (TAVI) or ballon angioplasty (BA) for the treatment of severe aortic stenosis. The subjects were admitted at the Cardiology department of the Faculty Hospital of Hradec Králové, Czech Republic. Two of these patients had BA before TAVI (one 8 months before and the second patient 1 month before), one of them needed BA 3 months after TAVI due to perivalvular leak. We then divided the patients into diabetic and non-diabetic subjects. The study was approved by local ethical committee and all patients sign a written consent.

\section{Study design}

Fasting blood samples were obtained immediately before and then $24 \mathrm{~h}, 72 \mathrm{~h}$ and one month 
after the cardiac procedure from every patient. Blood was drawn and centrifuged immediately. The serum was then aliquoted and stored at $-80^{\circ} \mathrm{C}$.

Table 1. Characteristics of subjects.

\begin{tabular}{lll}
\hline & Non DM & DM \\
\hline$n$ & 23 & 21 \\
Age (years) & $84.4 \pm 0.7$ & $79.2 \pm 1.6$ \\
Male & 10 & 10 \\
Female & 13 & 11 \\
BMI (kg/m $\left.{ }^{2}\right)$ & $26.7 \pm 4.9$ & $28.6 \pm 0.9$ \\
Systolic BP (mm Hg) & $133 \pm 16$ & $133 \pm 19$ \\
Diastolic BP (mm Hg) & $78 \pm 9$ & $71 \pm 10$ \\
Total patients after TAVI & 20 & 16 \\
$\quad$ a) apical route & 5 & 4 \\
$\quad$ b) femoral route & 15 & 12 \\
Total patients after BA & 3 & 5 \\
Coronary artery disease & $17(74 \%)$ & $16(76 \%)$ \\
Peripheral artery disease & $2(9 \%)$ & $4(19 \%)$ \\
Carotid artery disease & $6(26 \%)$ & $1(5 \%)$ \\
Total cholesterol (mmol/l) & $4.43 \pm 1.10$ & $3.88 \pm 1.10$ \\
HDL-C (mmol/l) & $1.46 \pm 0.46$ & $1.27 \pm 0.34$ \\
LDL-C (mmol/l) & $2.58 \pm 0.96$ & $2.25 \pm 0.92$ \\
Triglycerides (mmol/l) & $1.24 \pm 0.60$ & $1.13 \pm 0.46$ \\
\hline
\end{tabular}

BMI - body mass index, BP - blood pressure, TAVI transcatheter aortic valve implantation, DM - diabetes mellitus, HDL-C - high-density lipoprotein concentration, LDL-C - lowdensity lipoprotein concentration, BA - balloon angioplasty.

\section{Analytical methods}

The levels of plasma VEGF were obtained using an enzyme-linked immunosorbent assay (ELISA) kit (Quantikine human VEGF, R\&D Systems, USA). Intraassay variations were $<6.7 \%$, and interassay variations were $<8.8 \%$. The detection range of the assay was $15.6-2000 \mathrm{pg} / \mathrm{ml}$. We included a control group using 50 healthy blood donors without diabetes mellitus or atherosclerotic cardiovascular disease, giving us a population with $39.8 \pm 9.4$ years of age, with a mean level of VEGF of $232.95 \pm 51.18 \mathrm{pg} / \mathrm{ml}$.

Serum levels of total cholesterol (enzymatic colorimetric method), LDL, HDL cholesterol (homogenous enzymatic colorimetric test) and triglycerides (enzymatic colorimetric test) were analyzed with automatic analyzer Modular (Roche/Hitachi) using reagents from Roche diagnostics $\mathrm{GmbH}$, Mannheim,
Germany. Levels of high sensitivity CRP (hsCRP) were measured by chemiluminescent immunometric assay (Immulite, DPC, USA). A value less than 0.05 denoted the presence of a statistically significant difference.

\section{Statistical methods}

The statistical evaluation was performed using SigmaStat (Systat Software, Chicago IL, USA). All data are expressed as mean $\pm \mathrm{SD}$, or as total number, or as median (lower quartile, upper quartile). The statistical significance was determined based on a probability level of less than 0.05. For comparison of the VEGF levels before and after the cardiac intervention, the paired t-test was used. The correlations between the levels of VEGF and other variables were calculated using Pearson's correlation coefficient. To calculate the differences between 2 groups (diabetic and nondiabetic, TAVI and BA), independent (unpaired) t-tests were used. The numerical data were tested according to normal distribution. Mann Whitney test was used to assess the differences between obese DM patients vs. non-DM patients and Wilcoxon test for the evaluation of differences between the individual phases of observation of DM and non-DM patients.

\section{Results}

Concerning in-hospital combined safety endpoints (all-cause mortality, major stroke, periprocedural myocardial infarction, life-threatening bleeding, major vascular complication, and acute kidney injury), one patient ( $3 \%$ ) died due to a cerebrovascular event after TAVI.

Besides the treatment of DM (Table 1), the patients were given statins (77\%), antiplatelet agents (91\%), B-blockers (93\%), diuretics (98\%), warfarin (7\%), LMWH (2\%), sartans (36\%), or ACE inhibitors (45\%). Among DM patients, $83 \%$ were treated by statins and $97 \%$ by antiplatelet drugs.

Plasma VEGF in DM $(\mathrm{P}=0.032)$ and non-DM $(\mathrm{P}<0.001)$ patients at the baseline was significantly higher in comparison to the healthy subjects before any intervention was done (Table 2).

The patients were then further divided into diabetic and nondiabetic groups to compare the levels of VEGF between them. In the diabetic group, all patients were included without differentiation, if they were on diet, peroral antidiabetics, or insulin therapy. Using the independent samples t-test, we concluded that the levels 
VEGF are statistically significantly different between them. Plasma VEGF significantly increased after the endovascular procedure in both groups (with and without $\mathrm{DM}, \mathrm{P}<0.05$ ) and returned to the baseline values after one month after treatment. However, the VEGF in DM patients was constantly significantly lower than in non diabetic patients $(\mathrm{P}<0.05)$ (Fig. 1). Recently, it has been shown that statins used in patients with type 2 diabetes reduced the serum concentration of VEGF (Dworacka et al. 2014), however when we analyzed our DM patients based on the concomitant use of statins, we did not measure any significant differences in plasma VEGF.

Table 2. Plasma VEGF in the non-DM and DM patients.

\begin{tabular}{lllll}
\hline Group & $\mathbf{n}$ & $\begin{array}{l}\text { Age } \\
\text { (years) }\end{array}$ & $\begin{array}{l}\text { Plasma VEGF } \\
(\mathbf{p g} / \mathbf{m l})\end{array}$ & $\mathbf{P}$ \\
\hline Non-DM & 23 & $84.4 \pm 0.7$ & $418(329-555)$ & - \\
DM & 21 & $79.2 \pm 1.6$ & $331(242-467)$ & 0.017 \\
\hline
\end{tabular}

Data are shown as medians (interquartile range). Plasma VEGF in healthy blood donors without diabetes mellitus or any atherosclerotic cardiovascular disease, aged $39.8 \pm 9.4$ years was $219(209-260) \mathrm{pg} / \mathrm{ml}$. Statistical significance is indicated by $P$ between non-DM and DM patients.

Plasma CRP concentration before treatment was non-significantly higher in the DM patients. Its level however increased with the endovascular intervention in both non-DM and DM patients 24 and $72 \mathrm{~h}$ after treatment. 1 month after treatment CRP returned to the baseline (Table 3).

There were no statistical differences between the diabetic and nondiabetic groups concerning levels of total cholesterol, HDL, LDL, and triglycerides as well as BMI, and systolic and diastolic blood pressures. There was not any significant correlation between VEGF and total cholesterol, HDL, LDL, and triglycerides as well as BMI, and systolic and diastolic blood pressures.

Furthermore, using the independent samples t-test we noticed that the levels of VEGF before and after the procedure are not statistically significant when comparing it between the TAVI and BA groups $(\mathrm{P}=0.55$ and $\mathrm{P}=0.75$, respectively). This observation concluded that the plasma VEGF significantly increased in the same proportion after manipulation with the aortic valve, regardless of the interventional method.

\section{Discussion}

In this study, we have shown that in elderly patients with nonrheumatic stenotic aortic valves, 1) there is a profile of raised plasma VEGF levels; 2) endovascular intervention with transcatheter aortic valve implantation or balloon angioplasty is associated with increases in plasma levels of VEGF and returns to the baseline values 1 month after treatment; 3) changes in plasma levels of VEGF are not related to indexes of metabolic control, i.e. total cholesterol, HDL, LDL, and triglycerides as well as BMI, and systolic and diastolic blood pressures; 4) plasma VEGF in DM patients was constantly significantly lower than in non diabetic patients, suggesting an altered metabolism of proangiogenic VEGF and thus neovascularization dysfunction by overt disease.

Several lines of evidences suggest that the mechanism of aortic valve degeneration is similar to that of atherosclerosis, and accordingly, more patients are suffering from degenerative aortic valve disease. Although the molecular mechanisms underlying the onset of aortic valve degeneration are largely unknown, research in this area is advancing rapidly. Among other factors, investigations into angiogenesis in the aortic valve have been reported (Hakuno et al. 2009). Having

Table 3. Plasma CRP in the non-DM and DM patients.

\begin{tabular}{llll}
\hline CRP $(\mathbf{m g} / \mathbf{l})$ & Non-DM & DM & P \\
\hline Before procedure & $2.91(1.91-4.37)$ & $3.40(2.54-7.46)$ & 0.139 \\
After $24 \mathrm{~h}$ & $23.80(15.32-43.97)$ & $28.00(12.72-45.07)$ & 0.860 \\
After $78 \mathrm{~h}$ & $67.10(26.40-127.00)$ & $68.30(22.30-97.80)$ & 0.488 \\
After 1 month & $5.67(3.24-8.54)$ & $3.80(2.00-6.23)$ & 0.059 \\
\hline
\end{tabular}

Plasma CRP (mg/l) in patients with advanced atherosclerosis and diabetes mellitus type 2 (DM) ( $\mathrm{n}=21$, age $79.2 \pm 1.6$ years) and nondiabetic subjects (non-DM) ( $n=23$, age $84.4 \pm 0.7$ years) with symptomatic severe aortic stenosis undergone endovascular therapy by transcatheter aortic valve implantation. Data are shown as medians (interquartile range). CRP was measured before treatment, $24 \mathrm{~h}$, $72 \mathrm{~h}$ and 1 month after treatment. $\mathrm{P}$ indicates statistical significance in non-DM patients in comparison to the DM patients. 
noted avascularity of normal cardiac valves, disturbances between crucial angiogenic and anti-angiogenic factors in human atherosclerotic valves have recently been identified and the role of vascular endothelial growth factor is being recognized. The normal cardiac valves have specific protective mechanisms to inhibit pathologic angiogenesis, and once avascularity is lost and pathologic vascular invasion occurs in these tissues, severe diseases may ensue. In contrast, histopathologic analysis of tissues from human calcified aortic valves typically shows the expression of the potent angiogenic factor VEGF with numerous blood vessels growing into these valves (Hakuno et al. 2009). The potent proangiogenic factors, VEGF, and its receptors, VEGF receptor 1 (VEGFR-1) and VEGFR-2, are all locally expressed in aortic valves and upregulated in stenotic valves (Soini et al. 2003). Possible sources of VEGF in aortic valves include endothelial cells, myofibroblasts (Rajamannan et al. 2005) and mast cells, which have been shown to release VEGF when activated/stimulated (Grutzkau et al. 1998). Raised plasma VEGF levels in our group of non-DM patients with nonrheumatic aortic stenosis are in agreement with that concept.

The procedure of transcatheter aortic valve implantation or balloon angioplasty for the treatment of aortic stenosis lead to a dramatic increase in plasma VEGF concentration. While myocardial infarction following TAVI is relatively rare, with reported rates in the range of one percent (Rodés-Cabau et al. 2010), myocardial injury that does not meet the universal definition of myocardial infarction appears to be more common, with reported troponin elevations in as many as 95 to 100 percent of patients (Barbash et al. 2013). The mechanism of extremely elevated VEGF levels post TAVI in our patients should be a finding on a similar basis to the study of Heeschen et al. (2003), where the patients with acute coronary syndrome were stratified into quartiles according to their measured plasma VEGF levels. Their study population was dichotomized according to the level of VEGF $0.3 \mathrm{pg} / 1$, and the patients with VEGF levels equal or above $0.3 \mathrm{pg} / 1 \mathrm{had}$ more frequently ST segment depression, transient ST-segment elevation, recurrent ischemia CK-MB elevation and troponin elevation. VEGF elevation thus correlated with the evidence of myocardial ischemia.

The patients with DM and nonrheumatic aortic stenosis showed a similar pattern of plasma VEGF as the non-DM patients in our study. Their plasma VEGF was significantly increased at the baseline, and further increased after TAVI or BA. These findings were in agreement with the previous studies of March et al. (2000) and Valabhji et al. (2001) who observed that serum VEGF increased significantly in diabetic patients compared with healthy control subjects. Malamitsi et al. (1998) reported the same observation that serum VEGF increased significantly in diabetic patients compared with control subjects, and added that diabetes is characterized by increased angiogenic response in various organs.

Recent observations made in human aortic valves from patients with AS demonstrated increased expression of CRP and showed that the amount of proinflammatory proteins increased with the progression of AS (Toli et al. 2008). Plasma CRP concentration before treatment was non-significantly higher in our aged DM patients. In agreement with the above findings its level increased with the endovascular intervention in both nonDM and DM patients 24 and $72 \mathrm{~h}$ after treatment. One month after treatment CRP concentration returned to the baseline. It has been proposed that inflammation plays a crucial intermediate role in the pathogenesis of glucose disorders in the elderly (Barzilay et al. 2011), thereby linking diabetes with a number of commonly coexisting chronic inflammatory conditions thought to originate from inflammatory mediators, such as CRP. An independent association of CRP with AS progression has been also previously documented by Galante et al. (2001) giving a new understanding of the physiological role of CRP in stenotic valves, by promoting local proinflammatory effects.

We report that plasma VEGF in our elderly DM patients with nonrheumatic aortic stenosis was constantly significantly lower than in non diabetic patients, both before TAVI or BA and after the endovascular procedure. Our findings are in consistence with the general debate regarding the role of VEGF in diabetes and atherosclerotic cardiovascular disease and add information regarding diabetic patients (Inoue et al. 1998, Blann et al. 2001, Malamitsi-Puchner et al. 2001). From literature, serum VEGF is not raised in children with type I diabetes compared with age matched controls (Malamitsi-Puchner et al. 2001).

Moreover, VEGF is raised in the patients with diabetes plus atherosclerosis, but not in the group with diabetes alone (Blann et al. 2002); and our data (Fig. 1) suggest that this may be also the case in the elderly DM patients. Atherosclerotic tissue, within the artery wall, plaque or in microvessels, overexpress VEGF (Inoue et al. 1998), and a positive correlation between coronary 


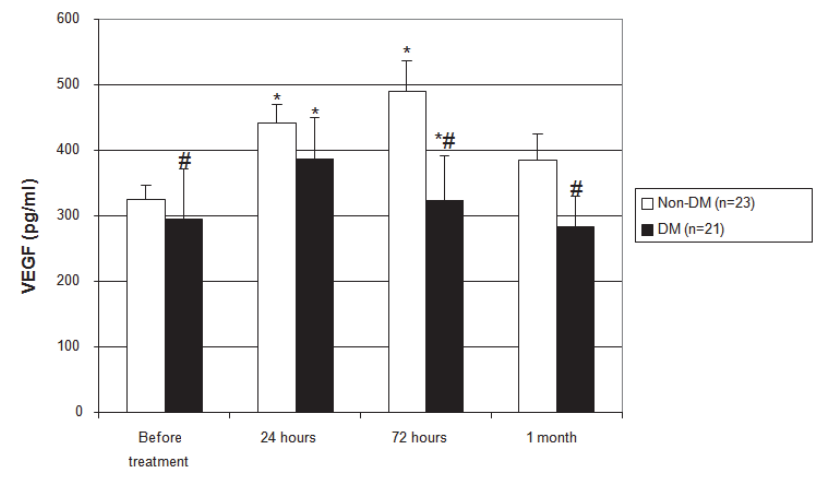

Fig. 1. Plasma VEGF before and after endovascular procedure in non-DM and DM patients. Vascular endothelial growth factor (VEGF) in patients with diabetes mellitus type 2 (DM) $(n=21$, age $79.2 \pm 1.6$ years) and non-diabetic subjects (non-DM) $(n=23$, age $84.4 \pm 0.7$ years) with symptomatic severe aortic stenosis undergone endovascular therapy by transcatheter aortic valve implantation $(n=35)$ or balloon angioplasty $(n=9)$. Measurements are expressed as mean \pm SD. VEGF was measured before treatment, $24 \mathrm{~h}, 72 \mathrm{~h}$ and 1 month after treatment. Statistical significance is indicated by $* \mathrm{P}<0.05$ during the time, $\# \mathrm{P}<0.05$ DM vs. non-diabetic patients.

artery collaterals and intra-coronary artery levels of plasma VEGF has been reported (Fleisch et al. 1999). Although we found lowered plasma VEGF levels in the group of patients with nonrheumatic aortic stenosis and $\mathrm{DM}$, but not in those without DM, it is not clear whether, overall, VEGF levels are reduced in diabetic atherosclerosis free cases. It is therefore curious that plasma VEGF levels were lower in patients within the diabetic group (Fig. 1). The reasons for lower plasma VEGF in our elderly DM with aortic stenosis are unclear. One of the possible explanation could be some metabolic or treatment aspects of diabetes and dyslipidaemia. When we analyzed our nonDM or DM patients based on their treatment modality (diet, per oral antidiabetic agents or insulin) or the concomitant use of statins or antiplatelet drug therapy, we did not measure any significant differences in plasma VEGF. Another explanation was highlighted in the observations of Valabhji et al. (2001) who reported a significant correlation between serum VEGF and glycaemic control detected by HbAlc. However, we do not have a complete set of data on HbAlc in our patients. Other metabolic parameters used in our study such as total cholesterol, HDL, LDL, and triglycerides as well as BMI did not correlate significantly with plasma VEGF. Other molecular mechanisms which were not measured in our study are the paradoxical changes in the expression of VEGF and its receptors in the myocardium and microvessels. The major cell types in cardiac tissue include cardiac myocytes, fibroblasts, and endothelial cells, all of which have been shown to produce VEGF. In the study of Chou et al. (2002), VEGF and its receptors in myocardium were decreased in insulin-resistant and diabetic states. One potential mechanism for decreased VEGF expression in myocardium in diabetic and insulin-resistant states was reported to be a loss of insulin-induced VEGF expression (Miele et al. 2000). Whether VEGF receptors could be similarly altered, and which signaling pathways may be involved, has yet to be assessed. Nevertheless, these findings are suggestive that the ability of insulin to induce VEGF expression may be inhibited in myocardium exposed to metabolically abnormal states such as insulin resistance, which is often present in poorly controlled diabetic and insulin-resistant patients. The decreased plasma VEGF in our DM patients may reflect the impaired production of VEGF, but we did not address that issue in our study and thus it would be unwise to speculate further without additional power.

Several limitations of our study should be taken into account. The first and most important drawback is the small number of subjects included in these investigations. However, patients were investigated four times during the observation period of one month to obtain a detailed impression of the plasma VEGF levels before and after transcatheter aortic valve implantation or balloon angioplasty for the treatment of aortic stenosis. The plasma concentrations of VEGF were measured up to one month of the experimental protocol but no longer, which might have underestimated the association between the investigated factors and VEGF during the natural development of the disease. Nevertheless, both groups were well matched. Second, the severity, and the duration of DM may not be the same in patients from the DM group. Thirdly, the mean age of these subjects implies the coexistence of multiple comorbidities, some of which may influence the VEGF metabolism. Additionally, the present study is focused on the patients with severe symptomatic aortic stenosis. Once the valve is heavily stenotic and calcified, inflammation may play less of a role in progression of AS than in a valve with less severe disease and the influence of DM on AS may be masked to some extent. Therefore, our results cannot be evaluated using the current approach and extrapolated on subjects with mild AS. Fourth, patients from DM group had significantly higher BMI $\left(28.3 \mathrm{~kg} / \mathrm{m}^{2}\right.$; 26.6-31.4) than the non-DM patients $\left(26.2 \mathrm{~kg} / \mathrm{m}^{2}\right.$; 23.2-28.2) (medians; interquartile range) $(\mathrm{P}=0.04)$, and obesity mediated production of atheroinflammatory 
markers is an important mechanism for its systemic elevation (Barzilay et al. 2011), which could partially influence the results. Finally, glycated hemoglobin, a retrospective DM indicator, has not been measured which could be another reason of the changes in plasma VEGF in DM patients (Valabhji et al. 2001).

In summary, the results of the present study bear out the involvement of increased plasma VEGF in advanced nonrheumatic aortic valve stenosis in elderly patients. Because plasma VEGF levels are selectively lower in patients with AS and diabetes we suggest that VEGF can act as a target for many new therapeutic modalities with the aim to induce angiogenesis and improve collateralization in the elderly diabetic patients with reparative endovascular therapy of aortic stenosis. Further studies are warranted to determine the role of angiogenic/anti-angiogenic balance including the role of both systemic and locally acting VEGF in aortic valve disease and in the patients with diabetes mellitus. Also, further investigations are needed to define whether interventions that directly target VEGF balance in diabetes might retard or reverse the progression of nonrheumatic aortic stenosis.

\section{Conflict of Interest}

There is no conflict of interest.

\section{Acknowledgements}

This work was supported by research projects IGA No. NT/12287-5 from the Ministry of Health of the Czech Republic and PRVOUK P37/12 from the Medical Faculty Charles University in Hradec Králové, Czech Republic.

\section{References}

ABACI A, OGUZHAN A, KAHRAMAN S, ERYOL NK, UNAL S, ARINC H, ERGIN A: Effect of diabetes mellitus on formation of coronary collateral vessels. Circulation 99: 2239-2242, 1999.

BLANN AD, BELGORE FM, CONSTANS J, CONRI C, LIP GYH: Vascular endothelial growth factor and its receptor, Flt-1, in the plasma of patients with hyperlipidaemia and atherosclerosis and the effect of lipid lowering therapy. Am J Cardiol 87: 1160-1163, 2001.

BLANN AD, BELGORE FM, MCCOLLUM CN, SILVERMAN S, LIP PL, LIP GY: Vascular endothelial growth factor and its receptor, Flt-1, in the plasma of patients with coronary or peripheral atherosclerosis, or type II diabetes. Clin Sci (Lond) 102: 187-194, 2002.

BARBASH IM, DVIR D, BEN-DOR I, BADR S, OKUBAGZI P, TORGUSON R, CORSO PJ, XUE Z, SATLER LF, PICHARD AD, WAKSMAN R: Prevalence and effect of myocardial injury after transcatheter aortic valve replacement. Am J Cardiol 111: 1337-1343, 2013.

BARZILAY JI, ABRAHAM L, HECKBERT SR, CUSHMAN M, KULLER LH, RESNICK HE, TRACY RP: The relation of markers of inflammation to the development of glucose disorders in the elderly: The Cardiovascular Health Study. Diabetes 50: 2384-2389, 2011.

BATTEGAY E: Angiogenesis: mechanistic insight, neovascular diseases, and therapeutic prospects. $J$ Mol Med 73: 333-346, 1995.

CELLETTI FL, WAUGH JM, AMABILE PG, BRENDOLAN A, HILKER PR, DAKE MD: Vascular endothelial growth factor enhances atherosclerotic plaque progression. Nature Med 7: 425-429, 2001.

CHOU E, SUZUMA I, WAY KJ, OPLAND D, CLERMONT AC, NARUSE K, SUZUMA K, BOWLING NL, VLAHOS CJ, AIELLO LP, KING GL: Decreased cardiac expression of vascular endothelial growth factor and its receptors in insulin-resistant and diabetic states a possible explanation for impaired collateral formation in cardiac tissue. Circulation 105: 373-379, 2002.

CONROTTO F, D'ASCENZO F, GIORDANA F, SALIZZONI S, TAMBURINO C, TARANTINI G, PRESBITERO P, BARBANTI M, GASPARETTO V, MENNUNI M, NAPODANO M, ROSSI ML, LA TORRE M, FERRARO G, OMEDÈ P, SCACCIATELLA P, MARRA WG, COLACI C, BIONDI-ZOCCAI G, MORETTI C, D'AMICO M, RINALDI M, GAITA F, MARRA S: Impact of diabetes mellitus on early and midterm outcomes after transcatheter aortic valve implantation (from a multicenter registry). Am J Cardiol 113: 529-534, 2014.

DVORAK HF, BROWN LF, DETMAR M, DVORAK AM: Vascular permeability factor/vascular endothelial growth, microvascular hyperpermeability, and angiogenesis. Am J Pathol 146: 1029-1039, 1995. 
DWORACKA M, KRZYŻAGÓRSKA E, WESOŁOWSKA A, BOROWSKA M, ISKAKOVA S, DWORACKI G: Statins in low doses reduce VEGF and bFGF serum levels in patients with type 2 diabetes mellitus. Pharmacol 93: 32-38, 2014.

FELMEDEN DC, SPENCER CG, BELGORE FM, BLANN AD, BEEVERS DG, LIP GY: Endothelial damage and angiogenesis in hypertensive patients: relationship to cardiovascular risk factors and risk factor management. Am J Hypertens 16: 11-20, 2003.

FERRARA N: Role of vascular endothelial growth factor in regulation of physiological angiogenesis. Am J Physiol Cell Physiol 280: C1358-C1366, 2001.

FLEISCH M, BILLINGER M, EBERLI FR, GARACHEMANI AR, MEIER B, SEILER C: Physiologically assessed coronary collateral flow and intracoronary growth factor concentrations in patients with 1- to 3-vessel coronary artery disease. Circulation 100: 1945-1950, 1999.

GALANTE A, PIETROIUSTI A, VELLINI M, PICCOLO P, POSSATI G, DE BONIS M, GRILLO RL, FONTANA C, FAVALLI C: C-reactive protein is increased in patients with degenerative aortic valvular stenosis. JACC $\mathbf{3 8}$ : 1078-1082, 2001.

GOODWIN AM: In vitro assays of angiogenesis for assessment of angiogenic and anti-angiogenic agents. Microvasc Res 74: 172-183, 2007.

GRUTZKAU A, KRUGER-KRASAGAKES S, BAUMEISTER H, SCHWARZ C, KOGEL H, WELKER P, LIPPERT U, HEESCHEN CH, DIMMELER S, HAMM CHW, BOERSMA E, ZEIHER AM, SIMOONS ML: Prognostic significance of angiogenic growth factor serum levels in patients with acute coronary syndromes. Circulation 107: 524-530, 2003.

HAKUNO D, KIMURA N, YOSHIOKA M, FUKUDA K: Molecular mechanisms underlying the onset of degenerative aortic valve disease. J Mol Med 87: 17-24, 2009.

HEESCHEN C, DIMMELER S, HAMM CW, BOERSMA E, ZEIHER AM, SIMOONS ML, CAPTURE (c7E3 AntiPlatelet Therapy in Unstable Refractory Angina) Investigators: Prognostic significance of angiogenic growth factor serum levels in patients with acute coronary syndromes. Circulation 107: 524-530, 2003.

HENZ BM, MOLLER A: Synthesis, storage, and release of vascular endothelial growth factor/vascular permeability factor (VEGF/VPF) by human mast cells: implications for the biological significance of VEGF. Mol Biol Cell 9: $875-884,1998$.

HOVIND P, TARNOW L, OESTERGAARD PB, PARVÁNY HH: Elevated vascular endothelial growth factor in type 1 diabetic patients with diabetic nephropathy. Kidney Int 75: S56-S61, 2000.

INOUE M, ITOH H, UEDA M, NARUKO T, KOJIMA A, KOMATSU R, DOI K, OGAWA Y, TAMURA N, TAKAYA K, TOSHIO I, YAMASHITA J, CHUN TH, MASATSUGU K, BECKER AE, NAKAO K: Vascular endothelial growth factor (VEGF) expression in human coronary atherosclerotic lesions. Circulation 98: 2108-2116, 1998.

JAWIEŃ J: New insights into immunological aspects of atherosclerosis. Pol Arch Med Wewn 118: 127-131, 2008.

KATZ R, WONG ND, KRONMAL R, TAKASU J, SHAVELLE DM, PROBSTFIELD JL, BERTONI AG, BUDOFF MJ, O'BRIEN KD: Features of the metabolic syndrome and diabetes mellitus as predictors of aortic valve calcification in the multi-ethnic study of atherosclerosis. Circulation 113: 2113-2119, 2006.

MALAMITS F, PUCHNER A, SARANDAKOO A, TZIOTIS A: Serum level of basic fibroblast growth factor and vascular endothelial growth factor in patients with diabetes mellitus. Red Res 44: 873-875, 1998.

MALAMITSI-PUCHNER A, SARANDAKOU A, TZIOTIS J, DAFOGIANNI C, BARTSOCAS C: Serum levels of basic fibroblast growth factor and vascular endothelial growth factor in children and adolescents with type 1 diabetes mellitus. Pediatr Res 44: 873-875, 1998.

MARSH S, NAKHOUL FM, SKORECKI K, RUBIN A, MILLER BP: Hypoxic induction of vascular endothelial growth factor is markedly decreased in diabetic individuals who do not develop retinopathy. Diabetes Care 23 : $1375-1380,2000$.

MIELE C, ROCHFORD JJ, FILIPPA N, GIORGETTI-PERALDI S, VAN OBBERGHEN E: Insulin and insulin-like growth factor-I induce vascular endothelial growth factor mRNA expression via different signaling pathways. J Biol Chem 275: 21695-21702, 2000. 
MOHTY D, PIBAROT P, DESPRÉS JP, CÔTÉ C, ARSENAULT B, CARTIER A, COSNAY P, COUTURE C, MATHIEU P: Association between plasma LDL particle size, valvular accumulation of oxidized LDL, and inflammation in patients with aortic stenosis. Arterioscler Thromb Vasc Biol 28: 187-193, 2008.

NATORSKA J, WYPASEK E, GRUDZIEŃ G, SOBCZYK D, MAREK G, FILIP G, SADOWSKI J, UNDAS A: Does diabetes accelerate the progression of aortic stenosis through enhanced inflammatory response within aortic valves? Inflammation 35: 834-840, 2012.

NGO MV, GOTTDIENER JS, FLETCHER RD, FERNICOLA DF, GERSH BJ: Smoking and obesity are associated with progression of aortic stenosis. Am J Geriatric Cardiol 10: 86-90, 2001.

OTTO CM, LIND BK, KITZMAN DW, GERSH BJ, SISOVICK DS: Associations of aortic valve sclerosis with cardiovascular mortality and morbidity in the elderly. NEJM 341: 142-147, 1999.

PATE GE: Association between aortic stenosis and hypertension. J Heart Valve Dis 11: 612-614, 2002.

RAJAMANNAN NM, NEALIS TB, SUBRAMANIAM M, PANDYA S, STOCK SR, IGNATIEV CI, SEBO TJ, ORTLEPP JR, PILLICH M, SCHMITZ F, MEVISSEN F, KOOS R, WEISS S, STORK L, DRONSKOWSKI $\mathrm{R}$, LANGEBARTELS $\mathrm{G}$, AUTSCHBACH R, BRANDENBURG $\mathrm{V}$, WOODRUFF S, KADEN JJ, HOFFMANN R: Lower serum calcium levels are associated with greater kalcium hydroxyapatite deposition in native aortic valves of male patients with severe calcific aortic stenosis. $J$ Heart Valve Dis 15: 502-508, 2006.

RODÉS-CABAU J, WEBB JG, CHEUNG A, YE J, DUMONT E, FEINDEL CM, OSTEN M, NATARAJAN MK, VELIANOU JL, MARTUCCI G, DEVARENNES B, CHISHOLM R, PETERSON MD, LICHTENSTEIN SV, NIETLISPACH F, DOYLE D, DELAROCHELLIÈRE R, TEOH K, CHU V, DANCEA A, LACHAPELLE K, CHEEMA A, LATTER D, HORLICK E: Transcatheter aortic valve implantation for the treatment of severe symptomatic aortic stenosis in patients at very high or prohibitive surgical risk: acute and late outcomes of the multicenter Canadian experience. JACC 55: 1080-1090, 2010.

ROSENGART TK, EDWARDS WD, MCCARTHY PM, BONOW RO, SPELSBERG TC: Calcified rheumatic valve neoangiogenesis is associated with vascular endothelial growth factor expression and osteoblast-like bone formation. Circulation 111: 3296-3301, 2005.

SASSO FC, TORELLA D, CARBONARA O, ELLISON GM, TORELLA M, SCARDONE M, MARRA C, NASTI R, MARFELLA R, COZZOLINO D, INDOLFI C, COTRUFO M, TORELLA R, SALVATORE T: Increased vascular endothelial growth factor expression but impaired vascular endothelial growth factor receptor signaling in the myocardium of type 2 diabetic patients with chronic coronary heart disease. JACC $\mathbf{4 6}$ : $827-834,2005$.

SOINI Y, SALO T, SATTA J: Angiogenesis is involved in the pathogenesis of nonrheumatic aortic valve stenosis. Hum Pathol 34: 756-763, 2003.

TOLI K, PARASKEVAS KI, POULAKOU MVV, AGROGIANNIS G, KAVANTZAS N, XANTHOPOULOS V, ILIOPOULOS DV, MANTAS I, PAPACHRISTODOULOU A, PATSOURIS E, MIKHAILIDIS DP, PERREA DN: Association between plasma levels and immunolocalization of cytokines in heart valve lesions: a possible target for treatment? Expert Opin Ther Targets 12: 1209-1215, 2008.

VALABHJI O, DHANJIL S, NICOLADES AN, ELKELES RS, SHARP P: Correlation between carotid artery dispensability and serum vascular endothelial growth factor concentrations in diabetic subjects and non diabetic subjects. Metabolism 50: 825-829, 2001.

YETKIN E, WALTENBERGER J: Molecular and cellular mechanisms of aortic stenosis. Int J Cardiol 135: 4-13, 2009. 